\title{
Extension - Upgrading Methane Using Ultra-Fast Thermal Swing Adsorption
}

\author{
Quarterly Report \\ January 1, 2006 - March 31, 2006 \\ by \\ Anna Lee Tonkovich
}

April 2006

DE-FC26-03NT41905

\author{
Velocys \\ 7950 Corporate Boulevard \\ Plain City, Ohio 43064 \\ Subcontractor \\ Joseph D'Amico \\ 6422 Oak Park Court \\ Linthicum, MD 21090
}


This report was prepared as an account of work sponsored by an agency of the United States Government. Neither the United States Government nor any agency thereof, nor any of their employees, makes any warranty, express or implied, or assumes any legal liability or responsibility for the accuracy, completeness, or usefulness of any information, apparatus, product, or process disclosed, or represents that its use would not infringe privately owned rights. Reference herein to any specific commercial product, process, or service by trade name, trademark, manufacturer, or otherwise does not necessarily constitute or imply its endorsement, recommendation, or favoring by the United States Government or any agency thereof. The views and opinions of authors expressed herein do not necessarily state or reflect those of the United States Government or any agency thereof. 


\section{Abstract}

The purpose of this project is to develop a cost effective technology for upgrading coal mine methane to natural gas pipeline quality. Nitrogen rejection is the most costly step with conventional technology and emerging competitive technology. Significant cost reductions to this step will allow for the cost effective capture and utilization of this otherwise potent greenhouse gas. The proposed approach is based on the microchannel technology platform that Velocys is developing to commercialize compact and cost efficient chemical processing technology. For this application, ultra fast thermal swing adsorption is enabled by the very high rates of heat transfer enabled by microchannels.

Natural gas upgrading systems have six main unit operations: feed compressor, dehydration unit, nitrogen rejection unit, deoxygenator, carbon dioxide scrubber, and a sales compressor. The NRU is the focus of the development program, and a bench-scale demonstration has been initiated. The Velocys NRU system targets producing methane with greater than $96 \%$ purity and at least $90 \%$ recovery for final commercial operation. A preliminary cost analysis of the methane upgrading system, including the Velocys NRU, suggests that costs below $\$ 2.00$ per million (MM) BTU methane may be achieved. The cost for a conventional methane upgrading system is well above \$2.30 per MM BTU, as benchmarked in an Environmental Protection Agency study.

Initial performance results for the Velocys TSA technology were promising. Velocys has also completed initial discussions with several prospective users of the technology and received positive market feedback. Some of the factors that create an attractive opportunity for the technology include the sustained high prices for natural gas, the emerging system of carbon credits, and continued focus on reducing coal mine emissions. While market interest has been confirmed, improvements and optimization are necessary to move the technology to a point that will enable commercial investment in the technology scale-up. In particular, prospective industry collaborators are interested in seeing validation that the technology can meet real-world conditions, including handling impurities, meeting purity and recovery targets (which requires low dead volume), and meeting cost and manufacturability goals.

In this quarter, the system adsorbent has been selected - a granular mesoporous carbon. An overall change to the system to move to a phase change fluid for heating and cooling has been projected to significantly reduce the thermal lag of adsorption and desorption unit. Modeling work using the properties of powder carbon has shown that the overall system performance can be achieved, thus negating the need for structured adsorbents. A revised testing protocol for powder adsorbents has been initiated.

$$
-1-
$$




\section{Table of Contents}

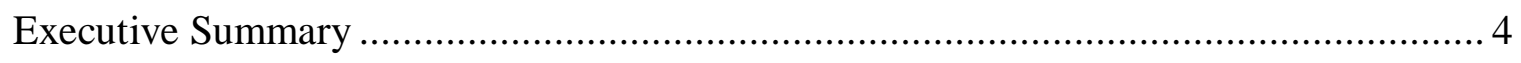

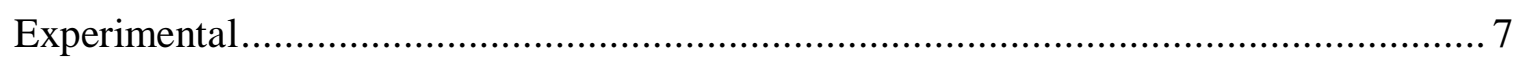

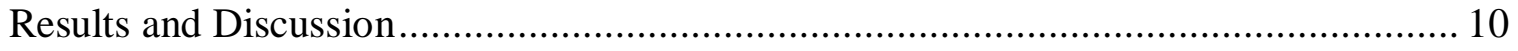

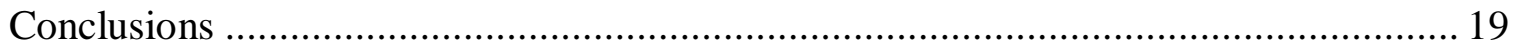

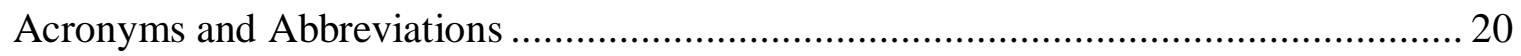

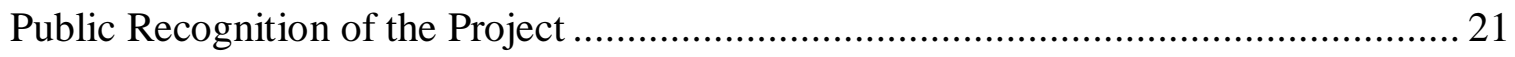




\section{Figures}

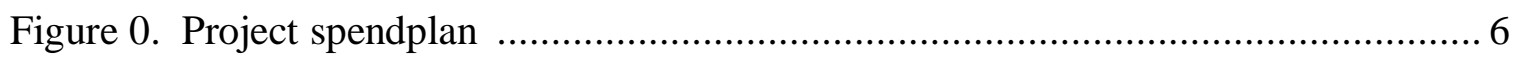

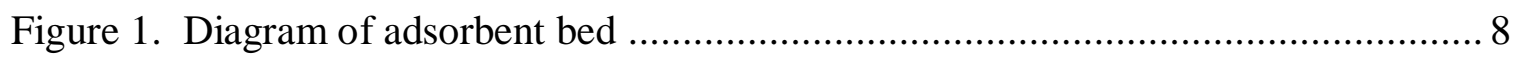

Figure 2. Sorbent temperatures $(\mathrm{k}=0.1 \mathrm{~W} / \mathrm{m}-\mathrm{K}$, gap $=0.08$ in, 30 to $70 \mathrm{C}) \ldots \ldots \ldots \ldots \ldots \ldots \ldots \ldots \ldots . . . .12$

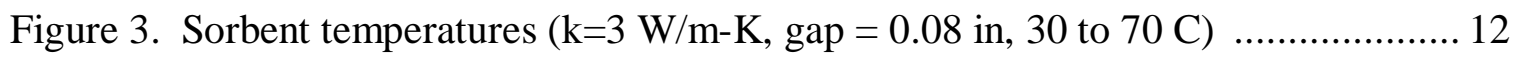

Figure 4. Sorbent temperatures $(\mathrm{k}=1 \mathrm{~W} / \mathrm{m}-\mathrm{K}$, gap $=0.08$ in, 30 to $70 \mathrm{C}) \ldots \ldots \ldots \ldots \ldots \ldots \ldots \ldots \ldots \ldots \ldots \ldots . . . . .13$

Figure 5. Sorbent temperatures $(\mathrm{k}=1 \mathrm{~W} / \mathrm{m}-\mathrm{K}$, gap $=0.08$ in, 10 to $90 \mathrm{C}) \quad \ldots \ldots \ldots \ldots \ldots \ldots \ldots \ldots \ldots \ldots . . . . .13$

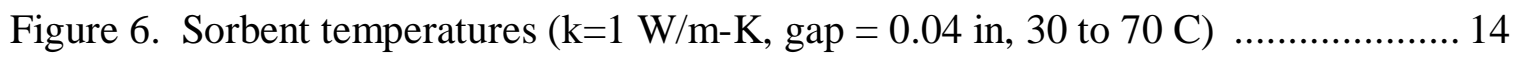

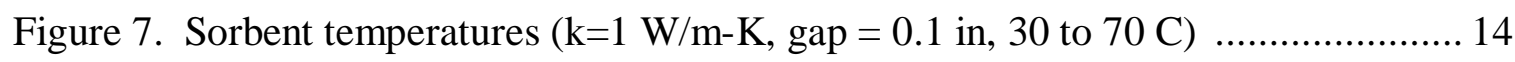

Figure 8. Sorbent temperatures $(\mathrm{k}=0.18 \mathrm{~W} / \mathrm{m}-\mathrm{K}$, gap $=0.03$ in, 20 to $70 \mathrm{C}) \ldots \ldots \ldots \ldots \ldots \ldots$

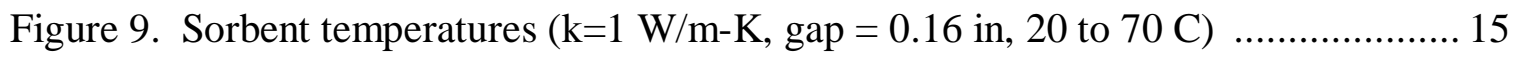

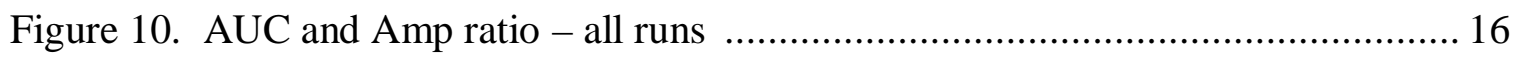

Figure 11. AUC and Amp ratio - effect of thermal conductivity only ........................ 16

Figure 12. AUC and Amp ratio - effect of adsorbent gap only …........................... 17

Figure 13. AUC and Amp ratio - combined effect of adsorbent gap and k ................ 17

Figure 14. AUC for 3 versus 6 seconds full cycle time ..................................... 18

Figure 15. Amplitude ratio for 3 versus 6 seconds full cycle time .......................... 18 


\section{Executive Summary}

The purpose of this project is to develop a cost effective technology for upgrading coal mine methane to natural gas pipeline quality. Nitrogen rejection is the most costly step with conventional technology and emerging competitive technology. Significant cost reductions to this step will allow for the cost effective capture and utilization of this otherwise potent greenhouse gas. The proposed approach is based on the microchannel technology platform that Velocys is developing to commercialize compact and cost efficient chemical processing technology. For this application, ultra fast thermal swing adsorption is enabled by the very high rates of heat transfer enabled by microchannels

The objective of the project extension over 24 months is to further evaluate the microchannel technology under real world processing conditions. Five main objectives are proposed:

- Identify one or more commercial absorbents that can meet the purity and recovery requirements for pipeline specifications

- Demonstrate that the absorbents can operate with real feed mixtures of coal mine methane streams

- Demonstrate that the bench-scale adsorber meets the purity, recovery, and durability requirements

- Confirm manufacturability of absorber units and identify critical development needs

- Show that the technology meets industry's economic targets for capital and operating costs

During the initial phase of the project, a number of key technical accomplishments were completed including:

- The thermal swing adsorption project demonstrated sufficient initial adsorbent differential capacity for methane and nitrogen on microporous carbon. The best differential capacity was at 100 psig between $40^{\circ} \mathrm{C}$ and $60^{\circ} \mathrm{C}$, where roughly $10 \mathrm{mg} / \mathrm{gm}$ methane and less than $1 \mathrm{mg} / \mathrm{gm}$ nitrogen were observed.

- A preliminary system and component design were performed to understand the requirements for process economics.

- An initial bench-scale demonstration was completed with a single cylindrical channel device, where a thermal swing time of 10 seconds for a bed differential temperature of $20^{\circ} \mathrm{C}$ was measured.

- A feed stream of $70 \%$ methane and $30 \%$ nitrogen was separated and purified to a mixture of $92 \%$ methane and $8 \%$ nitrogen with the use of an interstage purge to flush out the large dead volume on the test system.

The status of all tasks is listed below:

- Task 1: Evaluate improved and optimized adsorbents - complete

- The use of powder adsorbents as tested in the first phase of the program has been enabled by changing the heat transfer scheme from single phase convective heat transfer to phase change heat transfer

- Task 2: Evaluate feed mixtures with major contaminants - initiated

$$
-4-
$$


- A modified and simplified test system for measuring the impact of feed impurities has been designed and is in review

- Task 3: Demonstrate the bench-scale adsorber with reduced system dead volume and with a real feed mixture and improved adsorbent - pending

- Task 4: Develop preliminary manufacturing plan for full-scale microchannel units and identify critical development needs - pending

- Task 5: Update system design and cost based on thermal integration with coal-mine methane upgrading plants - pending

- Task 6: Commercialize Technology - pending

- Task 7: Project Management - ongoing 


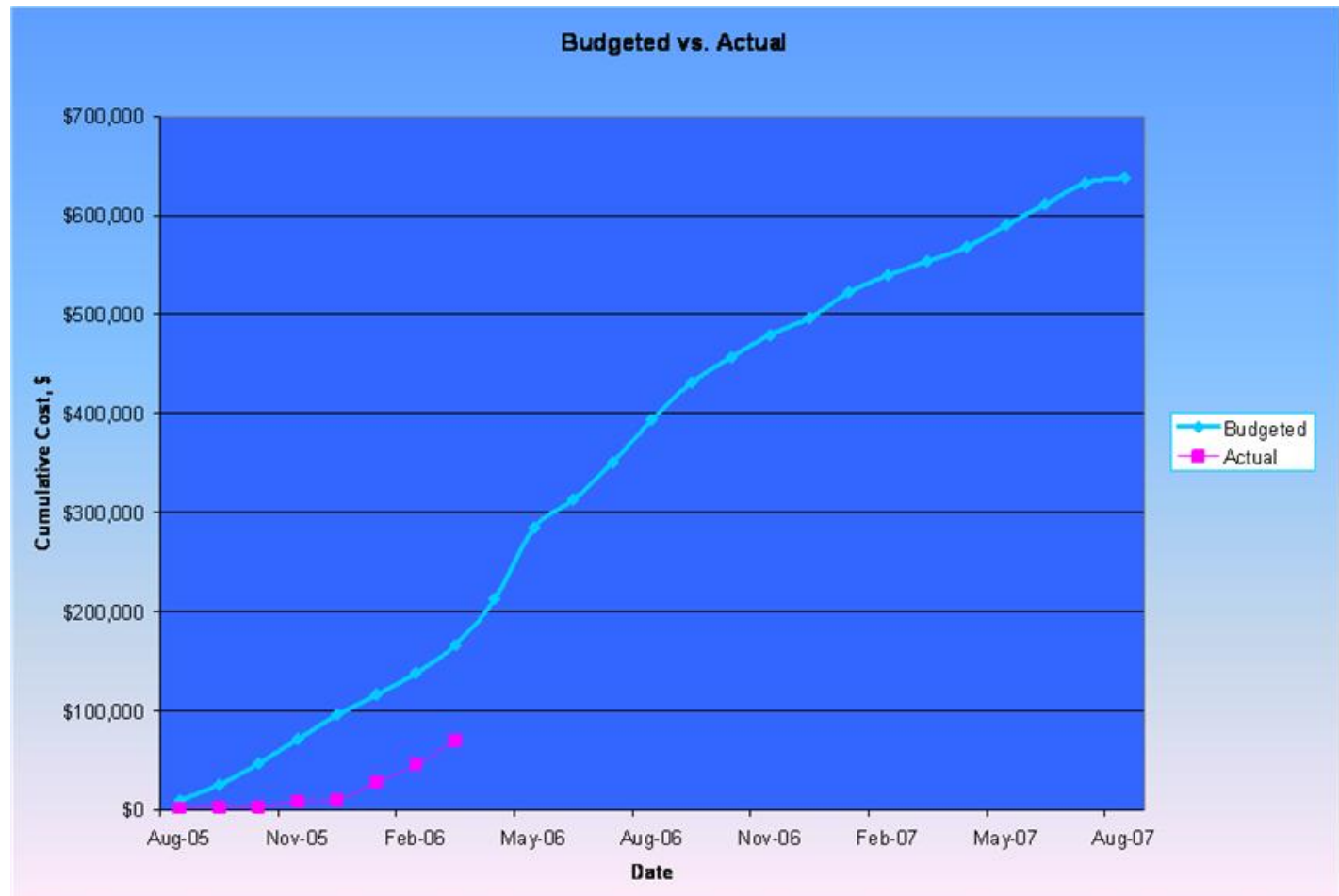

\section{Actual and Budgeted Cumulative Project Costs}

Figure 0. Project spendplan

The project has accelerated into a testing phase after selecting an appropriate adsorbent.

$$
-6-
$$

Project 41905, Upgrading Methane Using UltraFast Thermal Swing Adsorption, Velocys Inc. 


\section{Experimental}

The project initiated with an investigation into improved adsorbent options for use in the nitrogen rejection application. The evaluation has expanded in breadth to include structured adsorbents, including foams, felts, cloths, and the like.

Important parameters for consideration in evaluating new materials include:

- Thermal conductivity: to swing the bed faster

- Heat capacity: to reduce the amount of energy required to swing the bed

- Capacity: increase the uptake of methane

- Cost: integrate cost competitive and manufacturable structures into microchannel devices

The literature suggested several options for structured carbon adsorbents that may provide an effective thermal conductivity on the order of $1 \mathrm{~W} / \mathrm{m}-\mathrm{K}$.

A parallel effort was initiated to investigate the impact of a phase change heat transfer fluid on the thermal and adsorption properties versus the use of a convective heat transfer fluid. The modeling study included materials that ranged from $0.18 \mathrm{~W} / \mathrm{m}-\mathrm{K}$ (powder) to a highly effective structured adsorbent $(3 \mathrm{~W} / \mathrm{m}-\mathrm{K})$.

\section{Thermal Model Development:}

A network analysis model was built using the SINDA/FLUINT simulation tool. The model consisted of 7 nodes connected spatially in a 1-D orientation. Simulation output included well defined transient data for temperatures within the intervening wall between the adsorbent channel and heat transfer channel. 32 simulations were conducted to evaluate influences of changes in adsorbent bed material properties on thermal performance, given an oscillating (square-wave) boundary temperature. The boundary wall temperature was allowed to oscillate between a maximum range of $10^{\circ} \mathrm{C}$ to $80^{\circ} \mathrm{C}$, and a smaller range for some simulations.

Figure 1 illustrates a simplified diagram of the adsorbent bed, for thermal modeling purposes. In order to carry out this preliminary thermal analysis the following assumptions were made:

1. Heat flow was assumed to occur in one spatial dimension (1-D).

2. Material properties for the wall as well as adsorbent bed were assumed to be insensitive to temperature variation.

3. Adsorbent bed thermal properties were assumed to be characterized by "effective" properties applied to a uniform homogeneous material.

4. Other heat exchange surfaces within the model were assumed to be adiabatic or perfectly insulated. 
5. The temperature forcing function applied to the wall was an oscillating "square-wave" with a period of either 3 or 6 seconds. This time includes both the heating and cooling cycle

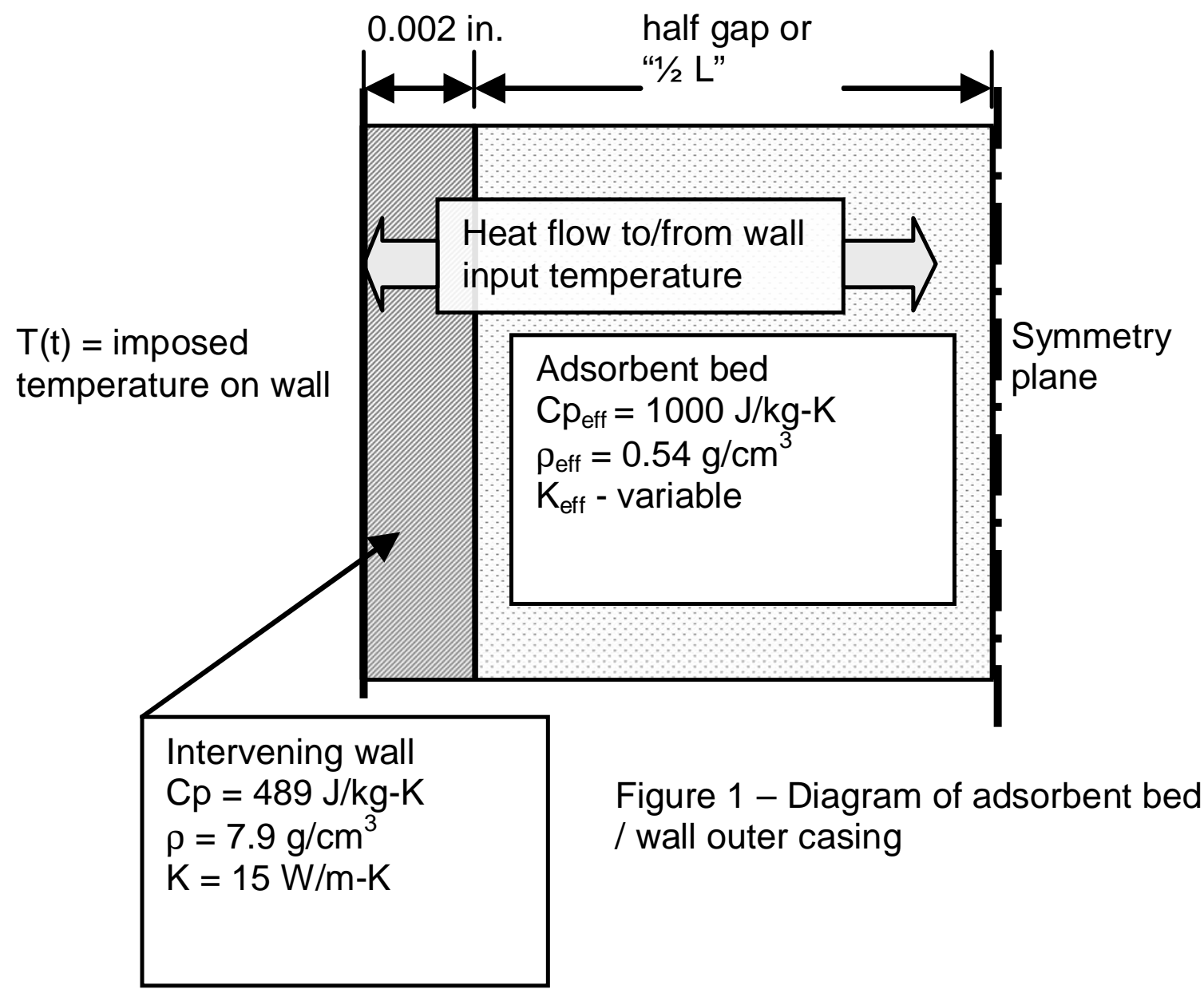

For the simulations, the boundary wall temperature was defined on the heat exchange fluid interface. Two transient temperatures (T2 and T3) were calculated within the intervening wall, where T2 was the mid point and T3 and the wall/adsorbent bed interface. Four transient temperatures were calculated within the adsorbent bed at equidistant locations to the bed centerpoint. All calculations were done with a symmetry plane down the center of the adsorbent bed. 


\section{Performance Metrics for Thermal Response}

\section{Area under the curve ratio or "AUC ratio"}

This metric starts with the area under the temperature versus time curve or the integral:

$$
\int\left(T(t)-T_{\min }\right) d t-\text { for one desorption phase, }(1 / 2 \tau)
$$

evaluated spatially at the adsorbent bed symmetry-plane. The term $\mathrm{T}_{\min }$ is the minimum temperature or minima for the oscillating adsorbent bed symmetry-plane. This integral is then divided by the corresponding area under the temperature / time curve for the boundary condition square wave, with the $\mathrm{T}_{\min }$ term equal to the minima for this boundary condition.

\section{Amplitude ratio or "Amp ratio"}

This metric is simply a ratio of the temperature extremes delta at the adsorbent symmetry plane divided by the temperature extremes delta for the boundary condition square wave. This relationship can be shown mathematically as:

$$
(\operatorname{Tmax}-\mathrm{Tmin})_{\mathrm{adsorbent}} /(\operatorname{Tmax}-\mathrm{Tmin})_{\text {square wave }}
$$




\section{Results and Discussion}

The transient thermal model simulated the impact of a phase change heat transfer fluid in the heat transfer channel, where the wall temperature remains constant during each half cycle and only the quality of gas or liquid changes as the adsorbent bed is either cooled or heated.

Variation in thermal conductivity - the adsorbent bed effective thermal conductivity was varied independently from $0.1 \mathrm{~W} / \mathrm{m}-\mathrm{K}$ to $3.0 \mathrm{~W} / \mathrm{m}-\mathrm{K}$. Results for $\mathrm{k}_{\mathrm{eff}}=0.1$ and $\mathrm{k}_{\mathrm{eff}}=3.0$ can be seen in Figures 2 and 3 for a half channel gap of 0.04 " or $1 \mathrm{~mm}$. The half channel gap is defined by the symmetry plane that runs down the center of the adsorbent channel. The black curves correspond to the input temperature boundary condition - the square wave. The colored curves depict material temperatures within the adsorbent bed; location \#4 being closest to the wall and location \#7 being at the plane of symmetry. Results are shown for a full cycle time of 3 seconds (half cycle for adsorption and half cycle for desorption) between 490 to 500 total elapsed seconds, where the transient thermal behavior had easily reached cyclic steady state.

As the thermal conductivity is increased, the ability for the adsorbent bed to follow the boundary wall temperature is enhanced. At the very lowest thermal conductivity $(0.1 \mathrm{~W} / \mathrm{m}-\mathrm{K})$, the resulting temporal temperature wave within the adsorbent bed exhibited a noticeable phase shift in the maximums and minimums relative to the input wall boundary temperature wave.

Variation in boundary wall temperature amplitude - the boundary wall temperature amplitude was varied such that the wall temperature oscillated from $30^{\circ} \mathrm{C}$ to $70^{\circ} \mathrm{C}$ or $20^{\circ} \mathrm{C}$ to $80^{\circ} \mathrm{C}$ or $10^{\circ} \mathrm{C}$ to $90^{\circ} \mathrm{C}$. Results for these variations in boundary wall temperatures are shown in Figures 4 and 5 . The extent of boundary wall temperature following and the shape of the adsorbent material temperature curves, is similar regardless of temperature amplitude.

Variation in adsorbent bed gap - the adsorbent bed channel gap was varied from 0.04 to 0.1 in. Results for these variations in adsorbent bed gap are shown in Figures 6 and 7. These simulation results demonstrate the expected proportionality between the adsorbent bed width and thermal resistance, i.e. as the gap is reduced, thus having less thermal resistance, the temperature following characteristics increase.

Variation in both adsorbent bed width and adsorbent bed thermal conductivity - a matrix of sensitivity runs were conducted for adsorbent bed gaps of 0.015 in. to 0.08 in. and the thermal conductivity between 0.18 and $1.0 \mathrm{~W} / \mathrm{m}-\mathrm{K}$. It should be noted that the $\mathrm{k}$ value of $0.18 \mathrm{~W} / \mathrm{m}-\mathrm{K}$ is the measured value for a powder carbon adsorbent as reported in the previous quarterly report.

Several simulations produced interesting results that are very promising for the low thermal conductivity powder. See Figures 8 and 9 for typical results. The thermal conductivity was increased from 0.18 to 1.0 - roughly a $5 x$ increase, while the gap was also increased by roughly $5 \mathrm{x}$. Both these changes together did not produce a zero change in thermal conductance, (conductance $=\mathrm{k} \cdot \mathrm{A} / \mathrm{L}$ ). The thermal behavior of the narrow gap and low thermal conductivity bed this is noticeably different - as a result of the decreased thermal inertia. 


\section{Metrics for Thermal Performance of the Adsorbent Bed}

Two metrics are defined for comparison of this adsorbent bed temperature following behavior: 1) area under the curve ratio (AUC ratio) and 2) amplitude ratio (Amp ratio). Two variations in adsorbent bed temperature characteristics occur as thermal resistance changes in the bed. The adsorbent bed temperature wave loses the input square-wave appearance, which can be quantified as a deviation in the area under the curve. Also the temperature amplitude deviates from that input. These two metrics allow for these complex transient characteristics to be quantified as two numbers for comparison purposes. AUC ratio and Amp ratio were computed at the adsorbent bed symmetry plane. Ratios that approach $100 \%$ indicate that the adsorbent bed material closely follows the input temperature boundary condition, which is desirable for high adsorbent utilization.

Figure 10 illustrates much of the data, presented as AUC ratio and Amp ratio versus the term: thermal conductivity divided by gap width $(\mathrm{k} / \mathrm{L})$. As $\mathrm{k} / \mathrm{L}$ increases, the AUC ratio and Amp ratio both approach $100 \%$. For designs with $\mathrm{k} / \mathrm{L}$ values of $>15[\mathrm{~W} / \mathrm{m}-\mathrm{K} / \mathrm{in}]$, the bed temperature amplitude is nearly $100 \%$ of that input and the AUC is $>80 \%$ of the square-wave input. Figure 11 shows the AUC ratio and Amp ratio when only the thermal conductivity is varied. The temperature following behavior correlates well with k/L. Figure 12 shows AUC ratio and Amp ratio for variations in the channel gap width. For this single independent variable change, gap width, thermal response correlates well with $\mathrm{k} / \mathrm{L}$. Figure 13 shows thermal performance behavior for changes in both thermal conductivity and gap width. This set of data was collected for only low $\mathrm{k} / \mathrm{L}$ values $(\mathrm{k} / \mathrm{L} \leq 10)$. Notice that no good correlation exists between the $\mathrm{k} / \mathrm{L}$ values and thermal performance. Figure 13 results illustrate the sometimes-competing influence of both thermal conductance and thermal inertia on adsorbent bed temperature following characteristics, which tend to confound results for $\mathrm{k} / \mathrm{L}<10$.

The boundary condition temperature period-of-oscillation $(\tau)$ was varied from the baseline $3 \mathrm{sec}$. to a value of $6 \mathrm{sec}$. This extended duration of time after the temperature swing caused the adsorbent bed to better follow the boundary condition temperature. Figures 14 and 15 show the AUC and Amp ratios for this variation in period-of-oscillation, $\tau$. Notice that the AUC ratio and Amp ratio tend to approach $100 \%$ as the frequency of oscillation is decreased. At this lower oscillation frequency, designs with $\mathrm{k} / \mathrm{L}$ values of $>10$ produced temperature amplitudes of nearly $100 \%$ and AUC ratios $>80 \%$. 
Figure 2 - S/F prediction of Sorbent Temperatures

Sorbent: keff $=0.1$, Cpeff $=1000$, rhoeff $=540,1 / 2$ gap $=0.04$ in.,

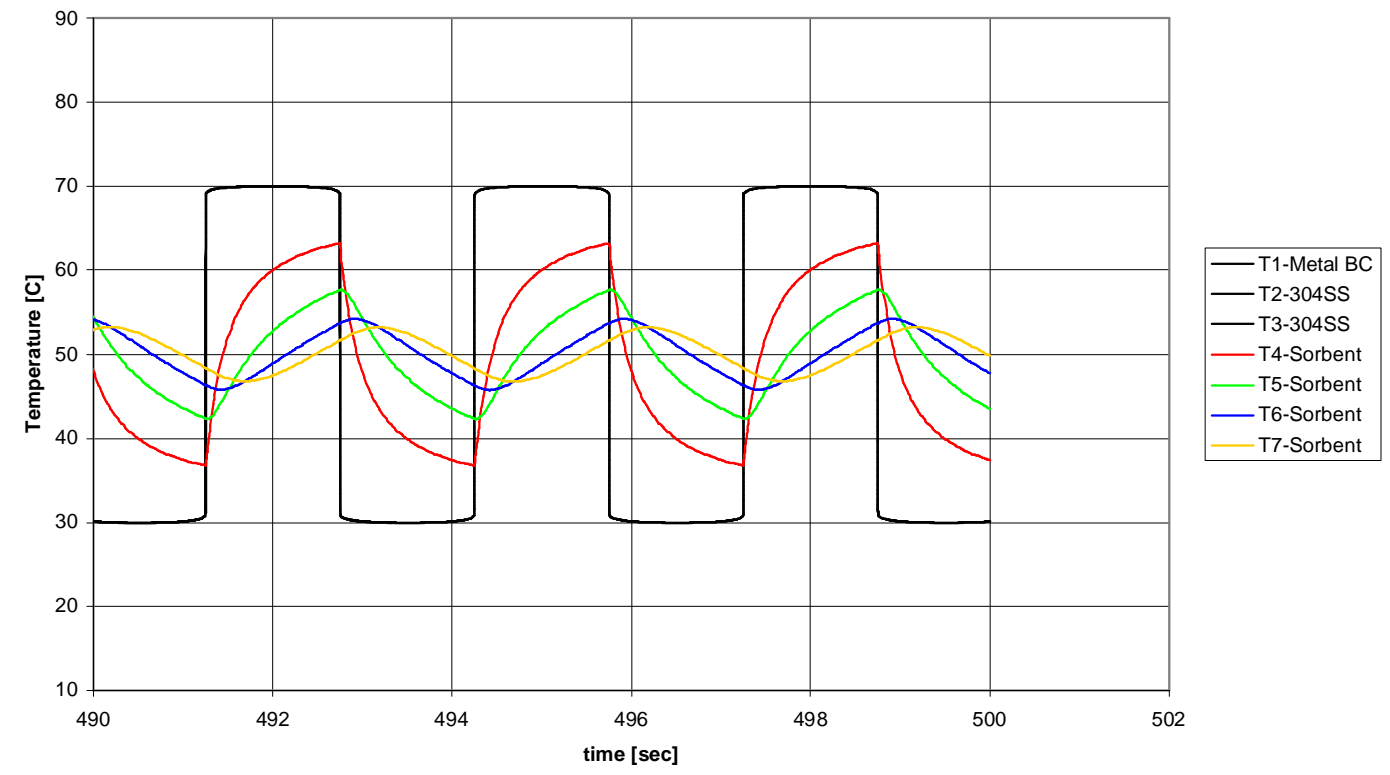

Figure 2. Sorbent temperatures $(\mathrm{k}=0.1 \mathrm{~W} / \mathrm{m}-\mathrm{K}$, gap $=0.08$ in, 30 to $70 \mathrm{C})$

Figure 3 - S/F prediction of Sorbent Temperatures

Sorbent: keff=3.0, Cpeff $=1000$, rhoeff $=540,1 / 2$ gap $=0.04$ in.,

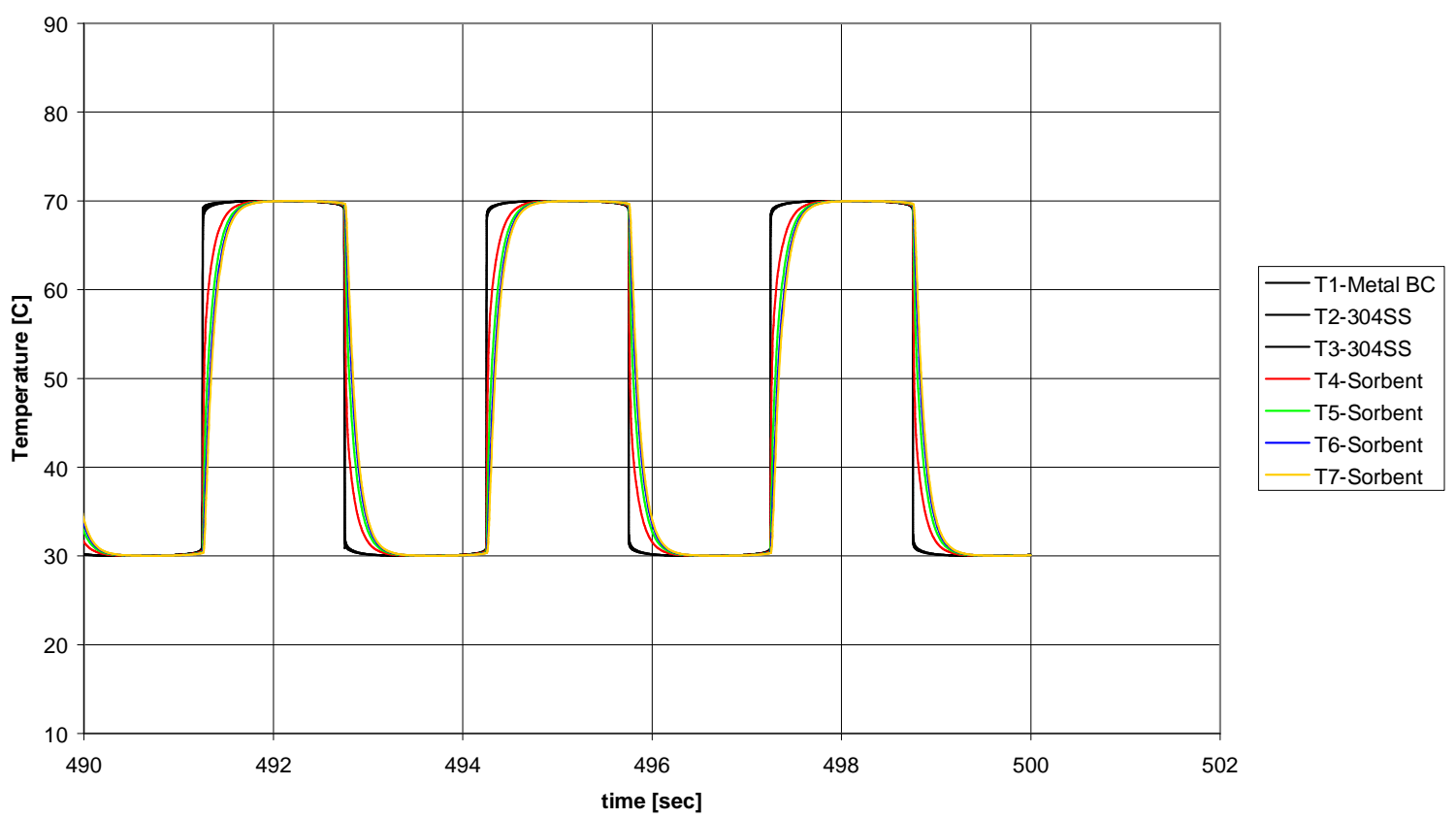

Figure 3. Sorbent temperatures $(k=3 \mathrm{~W} / \mathrm{m}-\mathrm{K}$, gap $=0.08$ in, 30 to $70 \mathrm{C})$

Project 41905, Upgrading Methane Using UltraFast Thermal Swing Adsorption, Velocys Inc. 
Figure 4 - S/F prediction of Sorbent Temperatures

Sorbent: keff=1.0, Cpeff=1000, rhoeff=540, 1/2gap=0.04 in.,

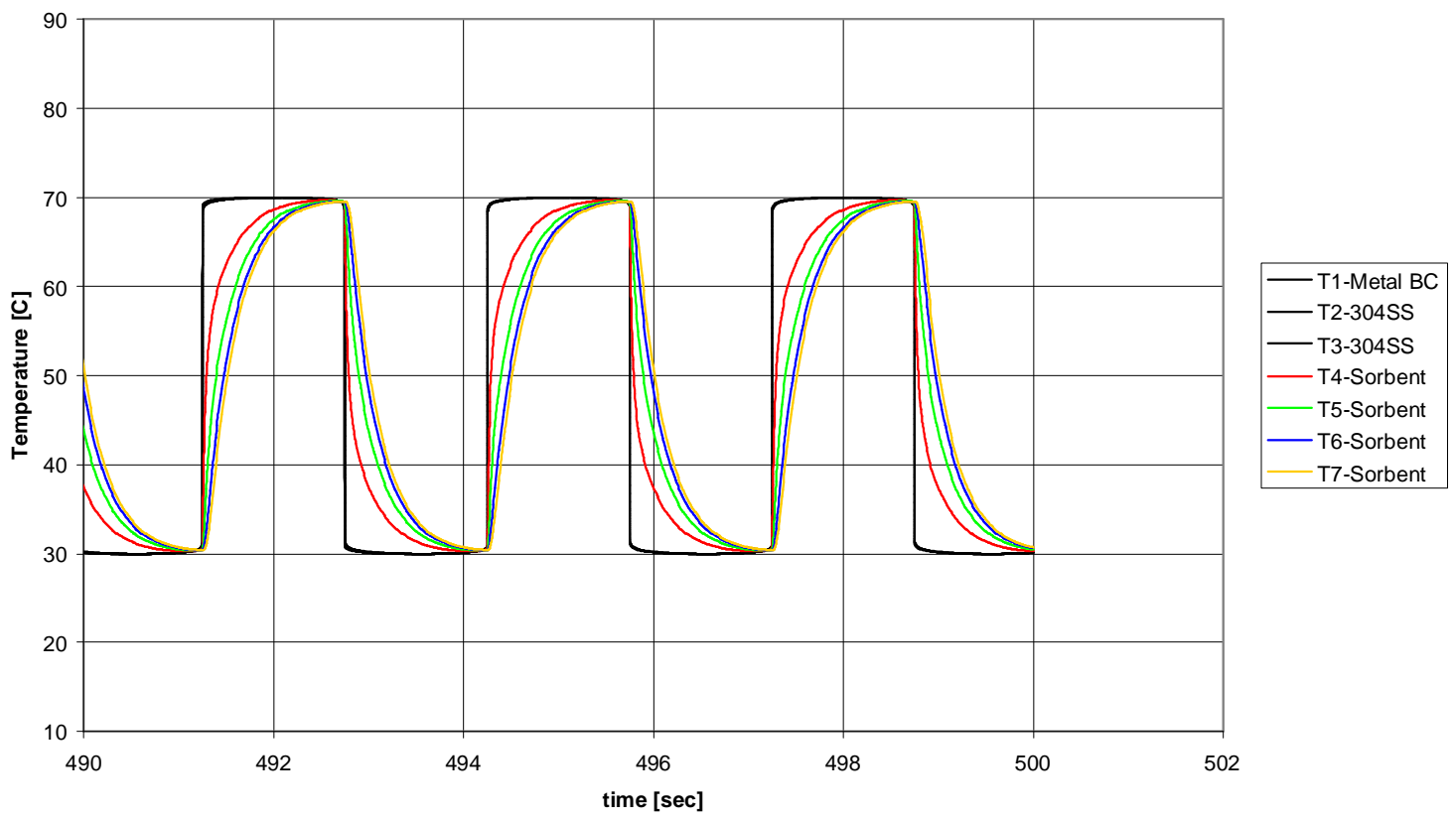

Figure 4. Sorbent temperatures $(\mathrm{k}=1 \mathrm{~W} / \mathrm{m}-\mathrm{K}$, gap $=0.08 \mathrm{in}, 30$ to $70 \mathrm{C})$

Figure 5 - S/F prediction of Sorbent Temperatures Sorbent: keff=1.0, Cpeff=1000, rhoeff=540, 1/2gap $=0.04$ in.,

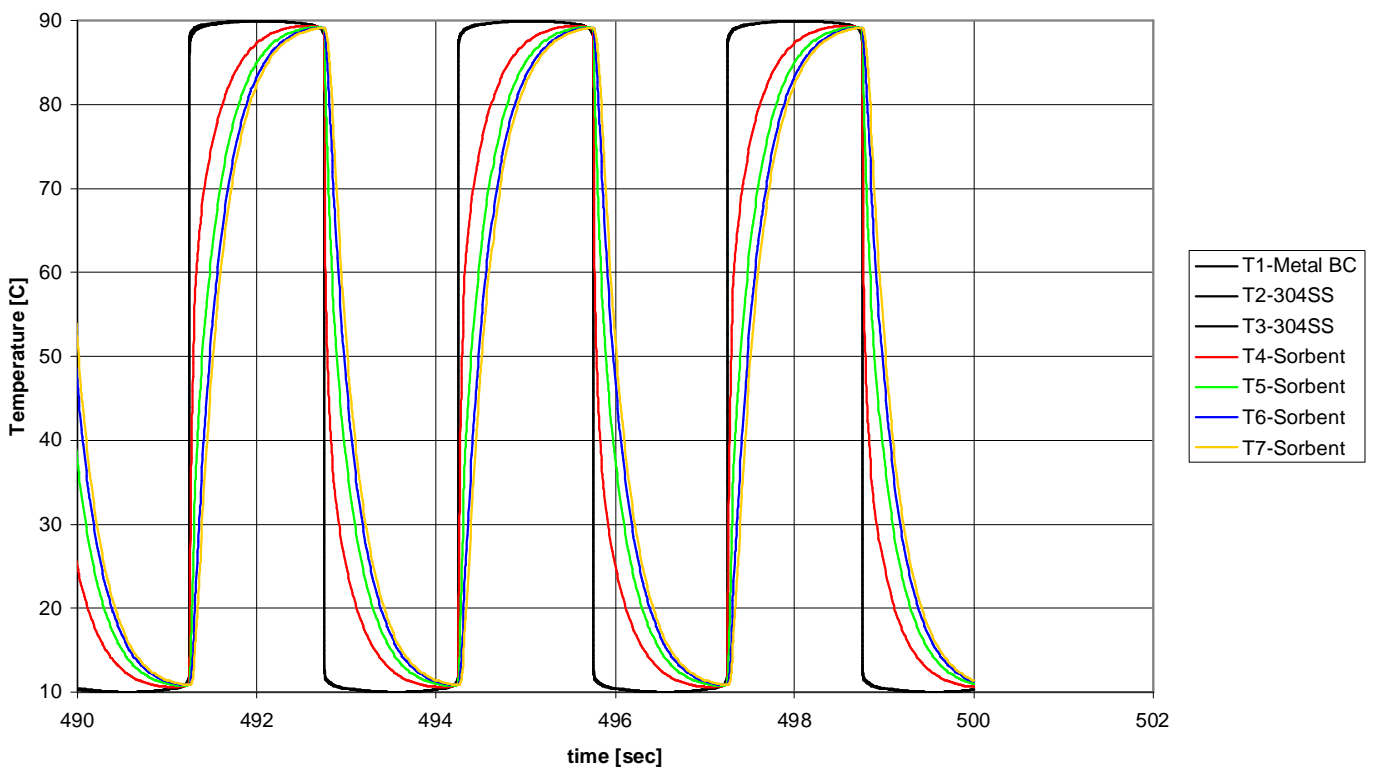

Figure 5. Sorbent temperatures $(\mathrm{k}=1 \mathrm{~W} / \mathrm{m}-\mathrm{K}$, gap $=0.08$ in, 10 to $90 \mathrm{C})$

Project 41905, Upgrading Methane Using UltraFast Thermal Swing Adsorption, Velocys Inc. 
Figure 6 - S/F prediction of Sorbent Temperatures

Sorbent: keff=1.0, Cpeff=1000, rhoeff $=540,1 / 2$ gap $=0.02$ in.,

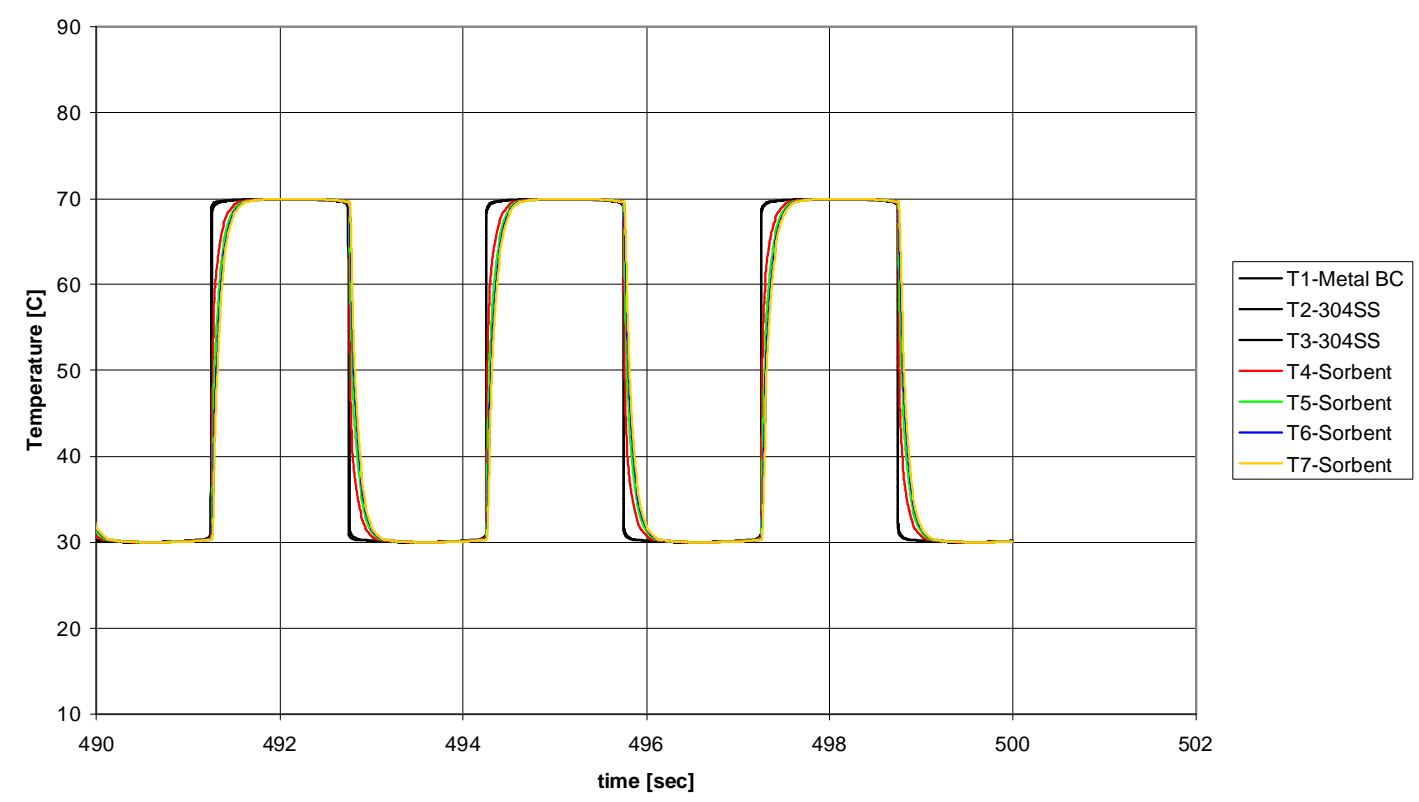

Figure 6. Sorbent temperatures $(\mathrm{k}=1 \mathrm{~W} / \mathrm{m}-\mathrm{K}$, gap $=0.04$ in, 30 to $70 \mathrm{C})$

Figure 7 - S/F prediction of Sorbent Temperatures Sorbent: keff=1.0, Cpeff=1000, rhoeff=540, 1/2gap=0.05 in.,

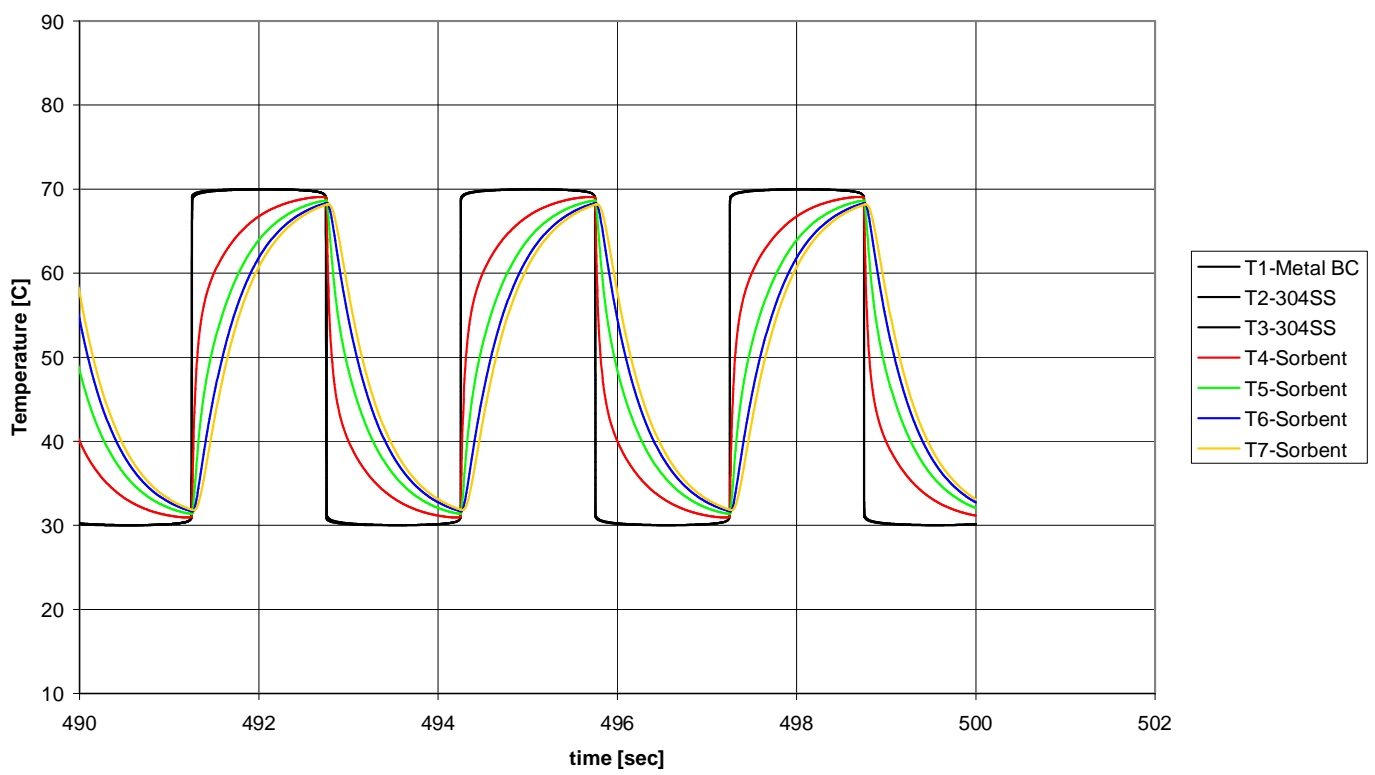

Figure 7. Sorbent temperatures $(k=1 \mathrm{~W} / \mathrm{m}-\mathrm{K}$, gap $=0.1 \mathrm{in}, 30$ to $70 \mathrm{C})$

Project 41905, Upgrading Methane Using UltraFast Thermal Swing Adsorption, Velocys Inc. 
Figure 8 - S/F prediction of Sorbent Temperatures Sorbent: keff $=0.18$, Cpeff $=1000$, rhoeff $=540,1 / 2$ gap $=0.015$ in.,

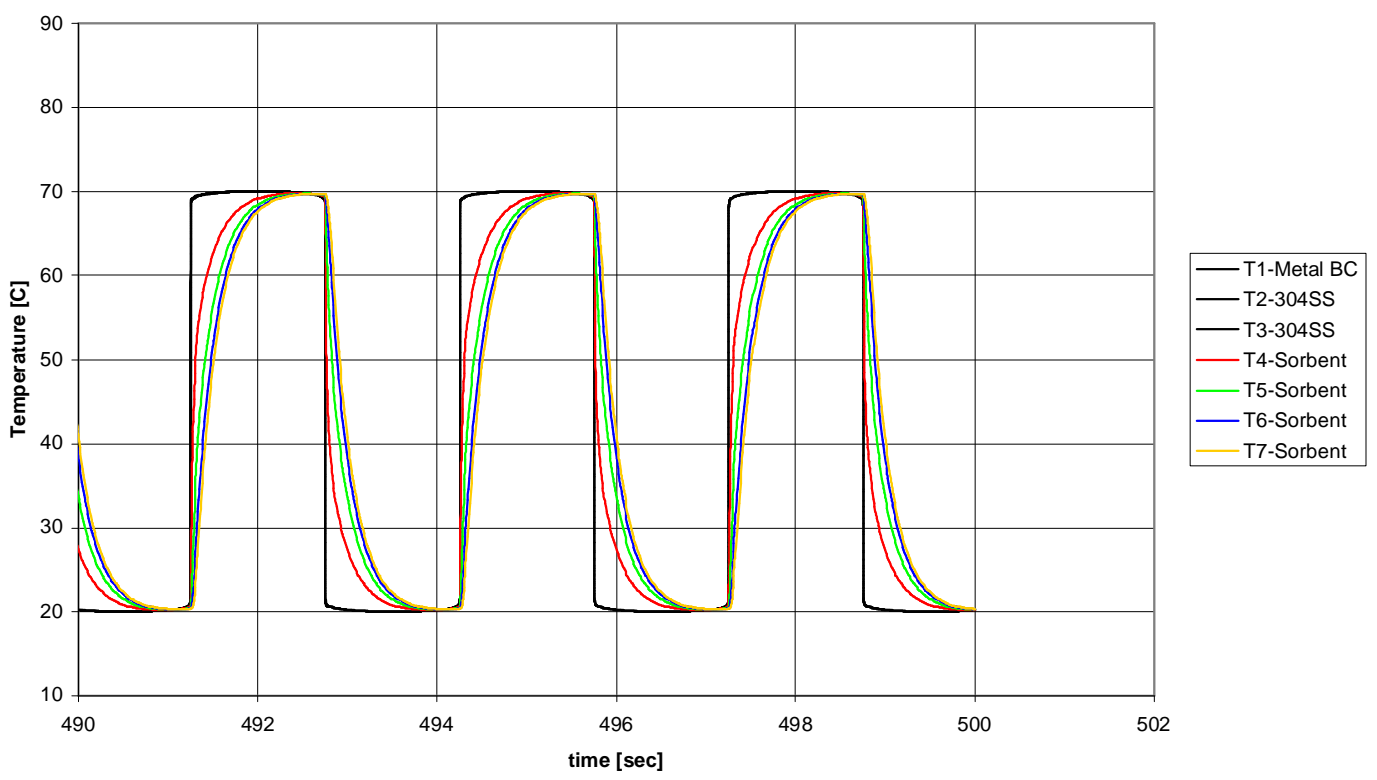

Figure 8. Sorbent temperatures $(\mathrm{k}=0.18 \mathrm{~W} / \mathrm{m}-\mathrm{K}$, gap $=0.03$ in, 20 to $70 \mathrm{C})$

Figure 9 - S/F prediction of Sorbent Temperatures Sorbent: keff=1.0, Cpeff=1000, rhoeff $=540,1 / 2$ gap $=0.080$ in.,

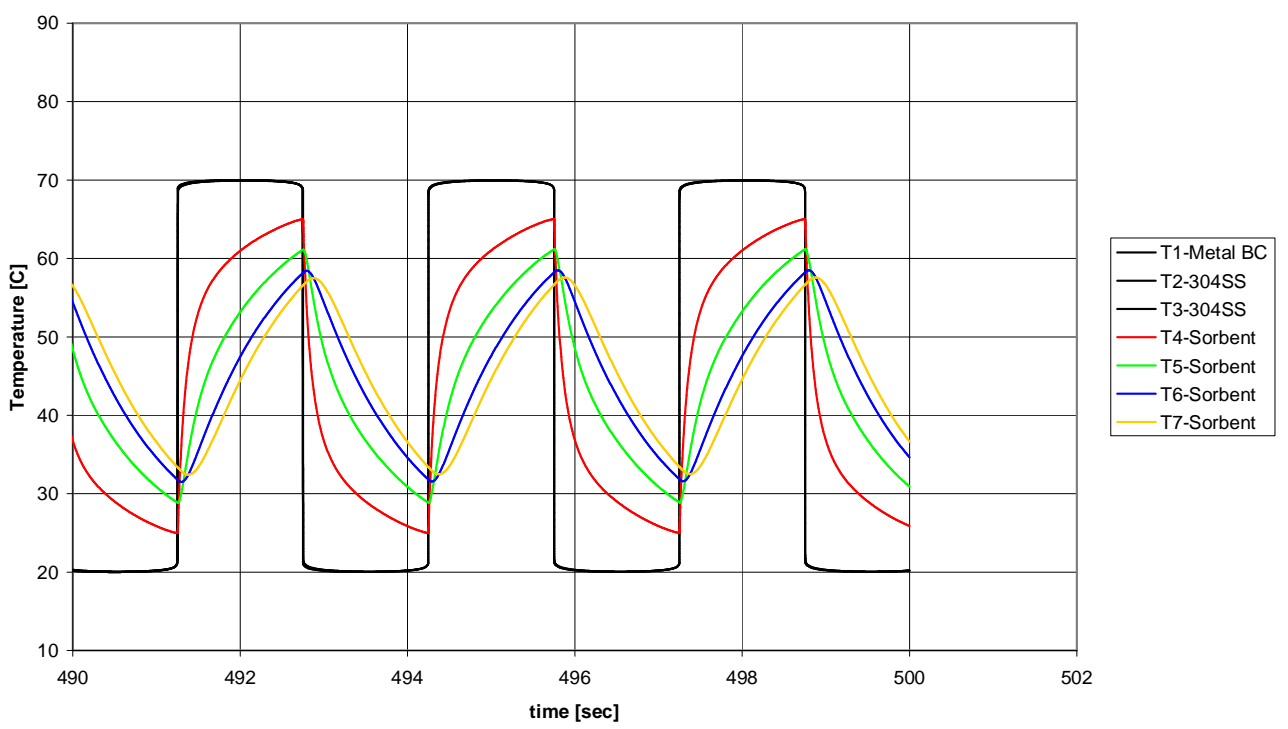

Figure 9. Sorbent temperatures $(\mathrm{k}=1 \mathrm{~W} / \mathrm{m}-\mathrm{K}$, gap $=0.16$ in, 20 to $70 \mathrm{C})$

Project 41905, Upgrading Methane Using UltraFast Thermal Swing Adsorption, Velocys Inc. 
Figure 10 - Effect of Adsorbent bed Conductance on Thermal Lag

Based on SINDA/FLUINT predictions, 1-D \& transient

Total data set for all sensitivity runs

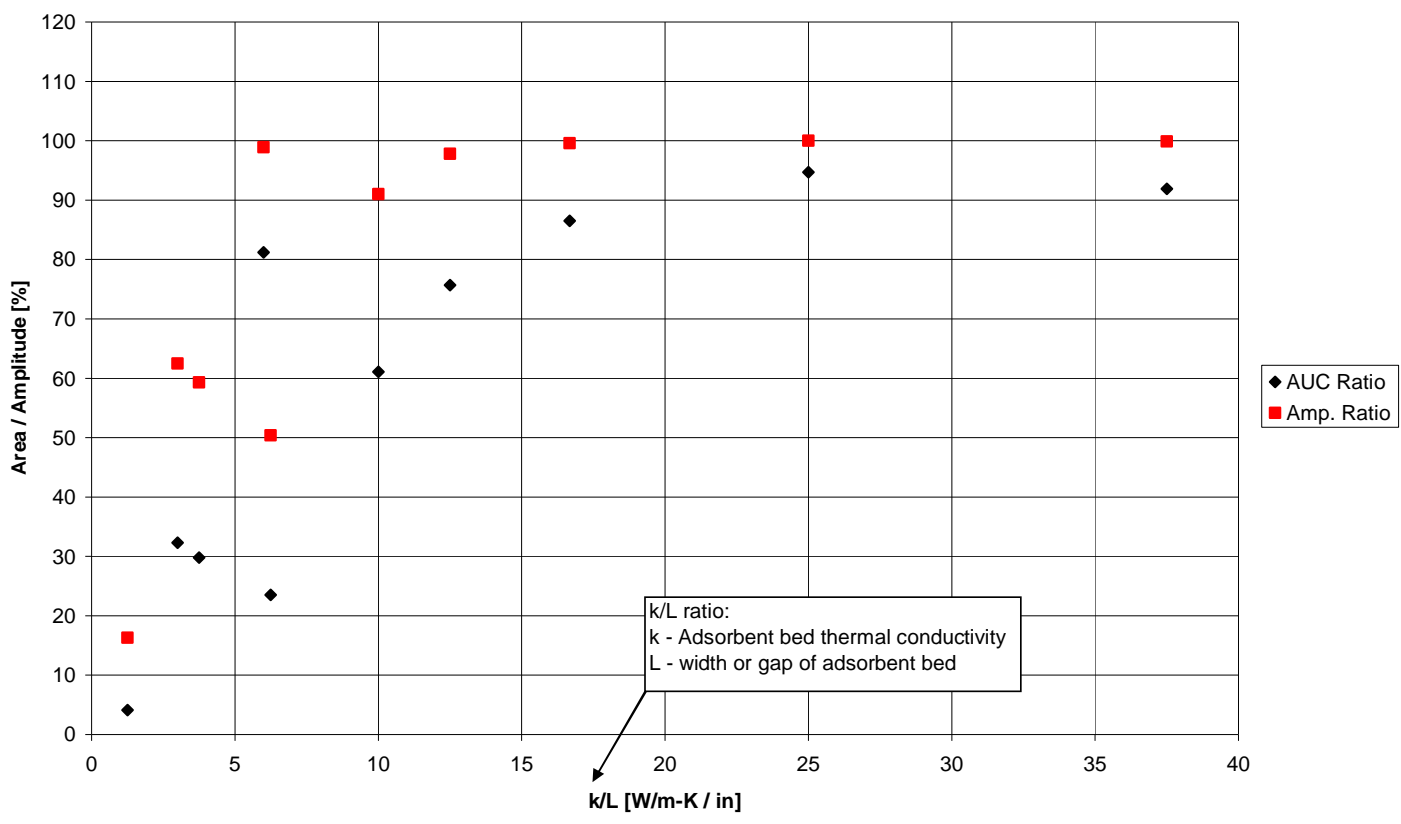

Figure 10. AUC and Amp ratio - all runs

Figure 11 - Effect of Adsorbent bed Thermal Conductivity on Thermal Lag Variation only in Adsorbent-bed Thermal Conductivity Based on SINDA/FLUINT predictions, 1-D \& transient

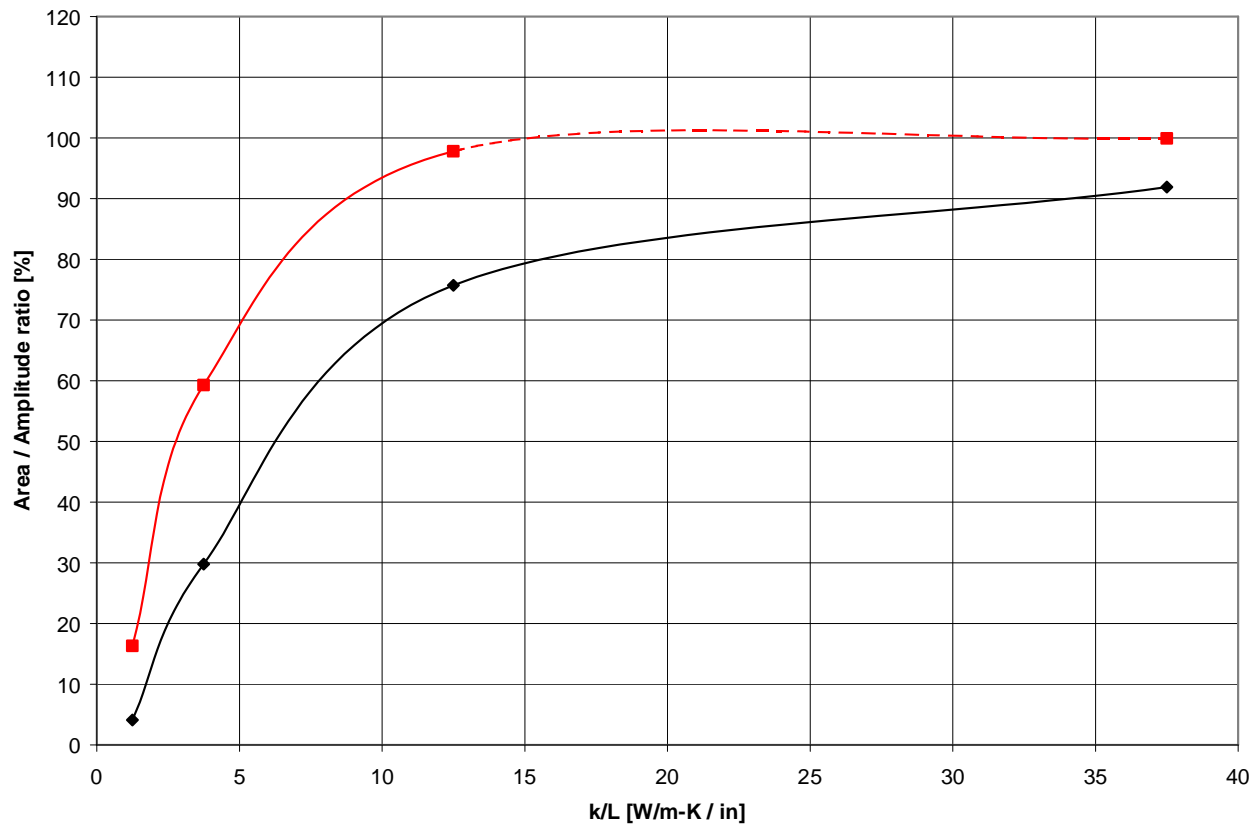

Figure 11. AUC and Amp ratio - effect of thermal conductivity only

Project 41905, Upgrading Methane Using UltraFast Thermal Swing Adsorption, Velocys Inc. 
Figure 12 - Effect of Adsorbent bed Gap on Thermal Lag

Variation only in Adsorbent-bed Gap Dimension

Based on SINDA/FLUINT predictions, 1-D \& transient

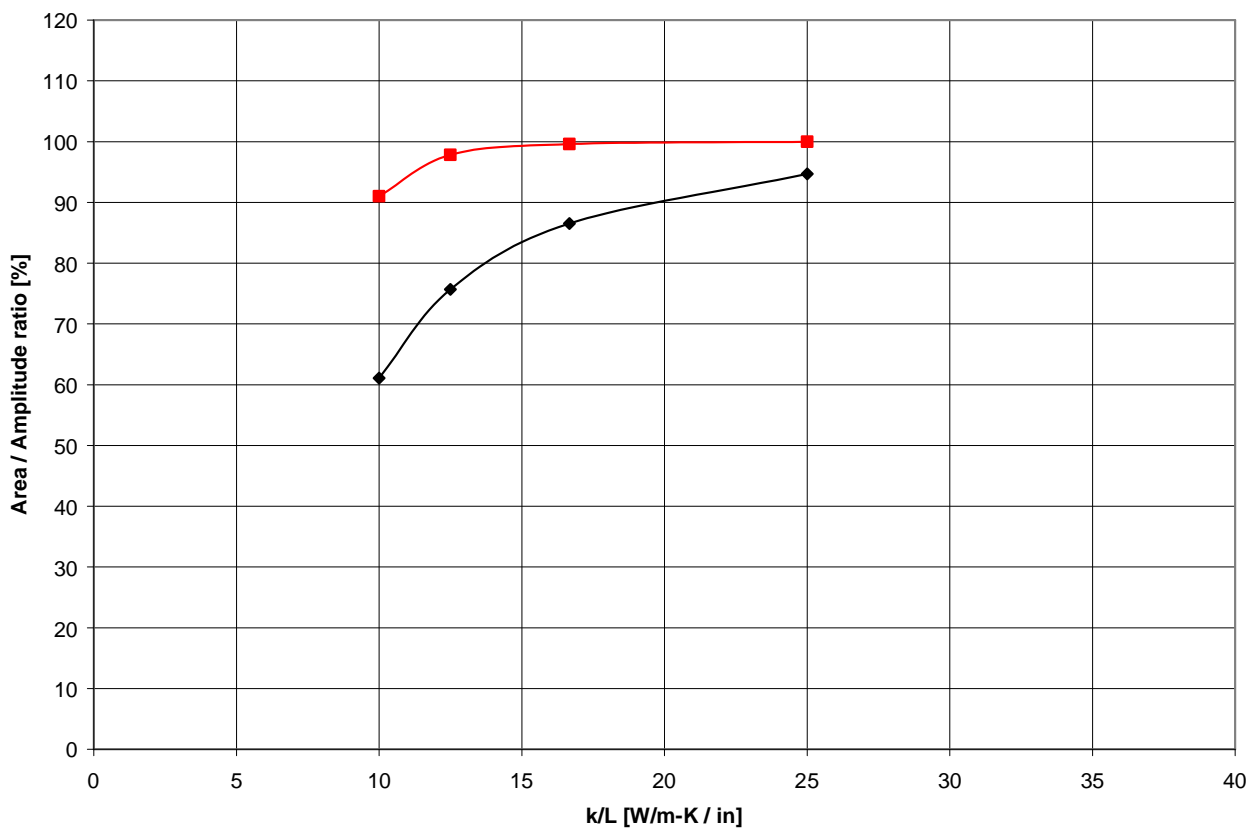

Figure 12. AUC and Amp ratio - effect of adsorbent gap only

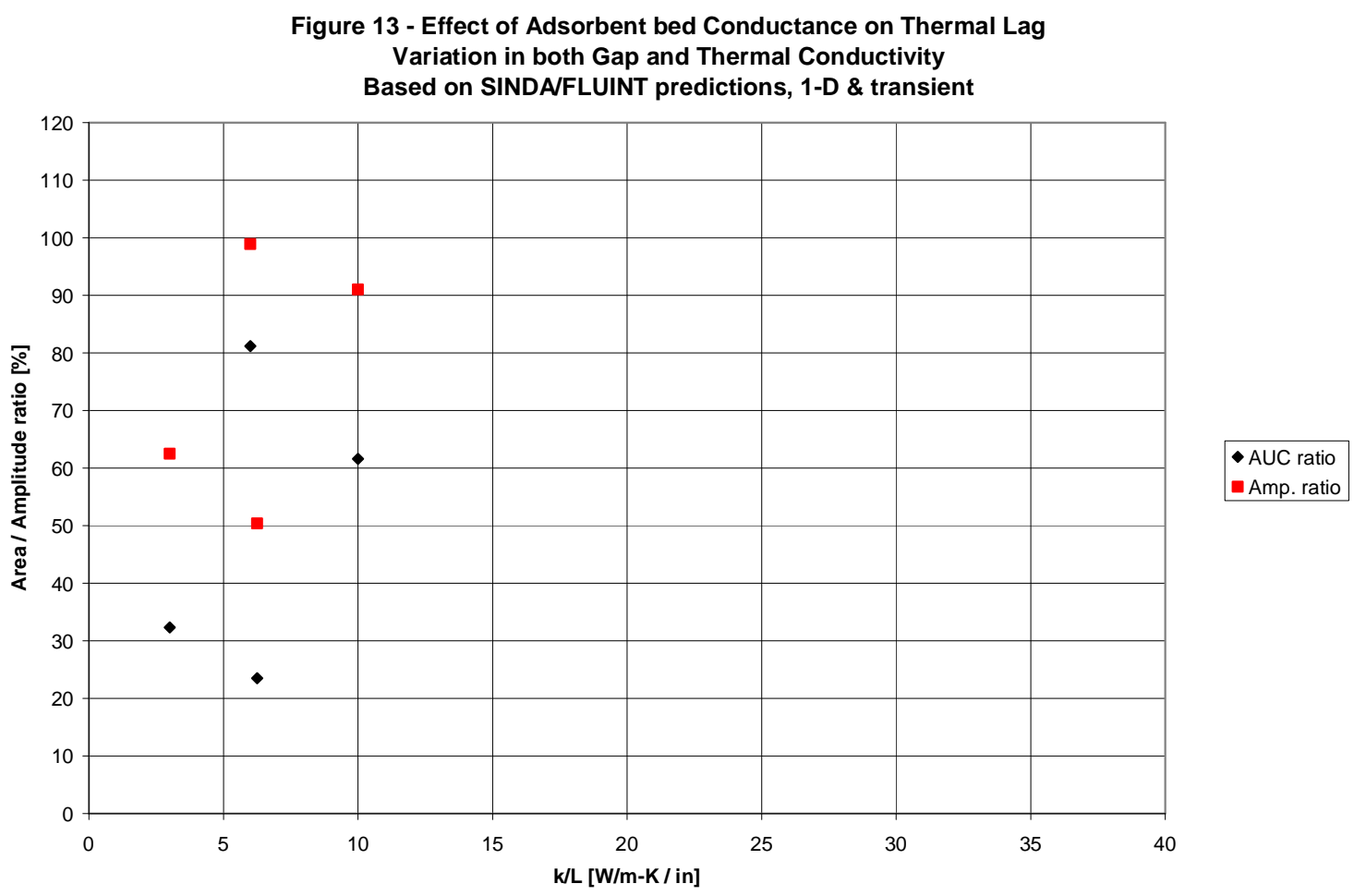

Figure 13. AUC and Amp ratio - combined effect of adsorbent gap and k

Project 41905, Upgrading Methane Using UltraFast Thermal Swing Adsorption, Velocys Inc. 
Fig 14 - Effect of Frequency of Oscillation on Thermal Lag Based on SINDA/FLUINT predictions, 1-D \& transient

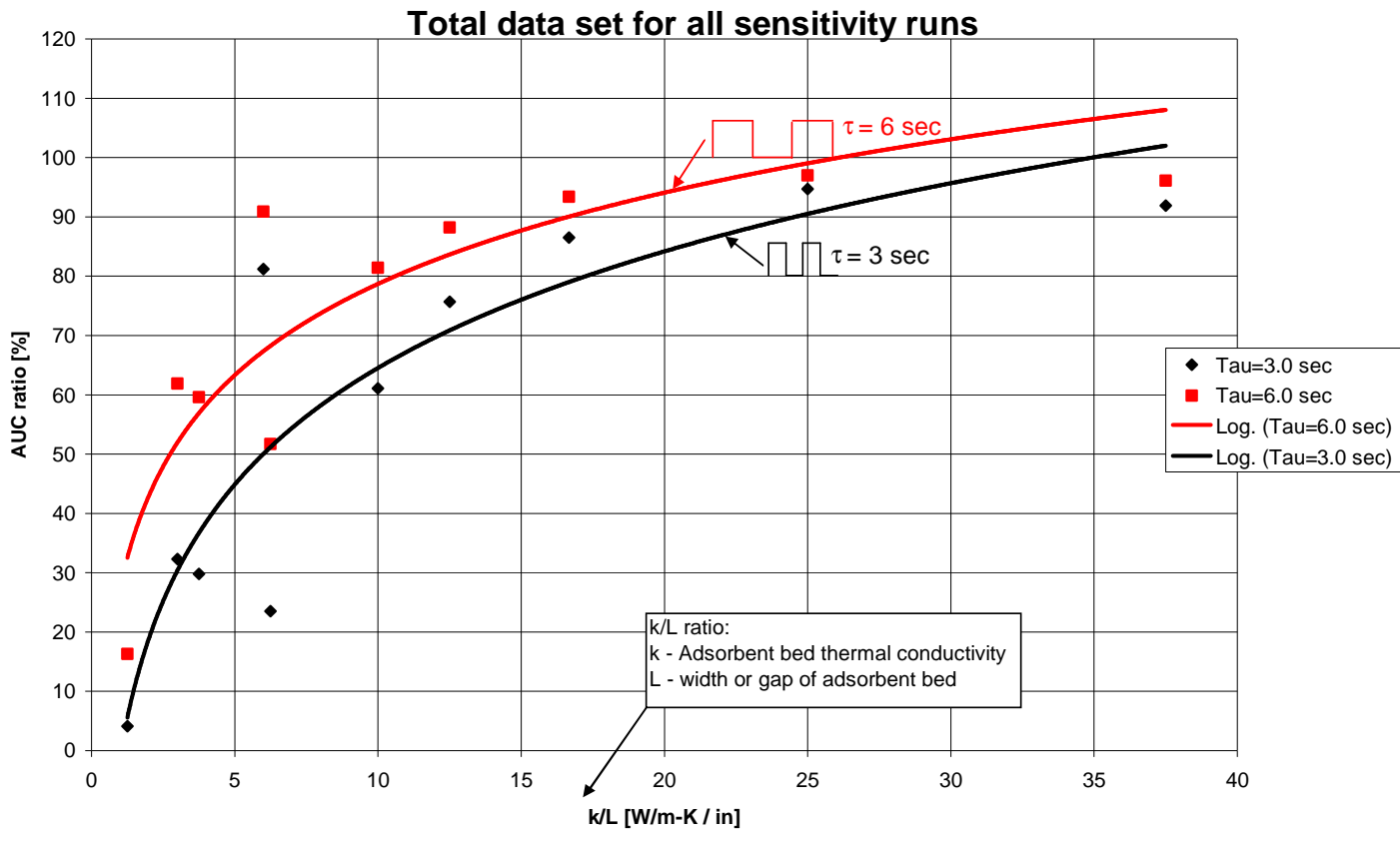

Figure 14. AUC for 3 versus 6 seconds full cycle time

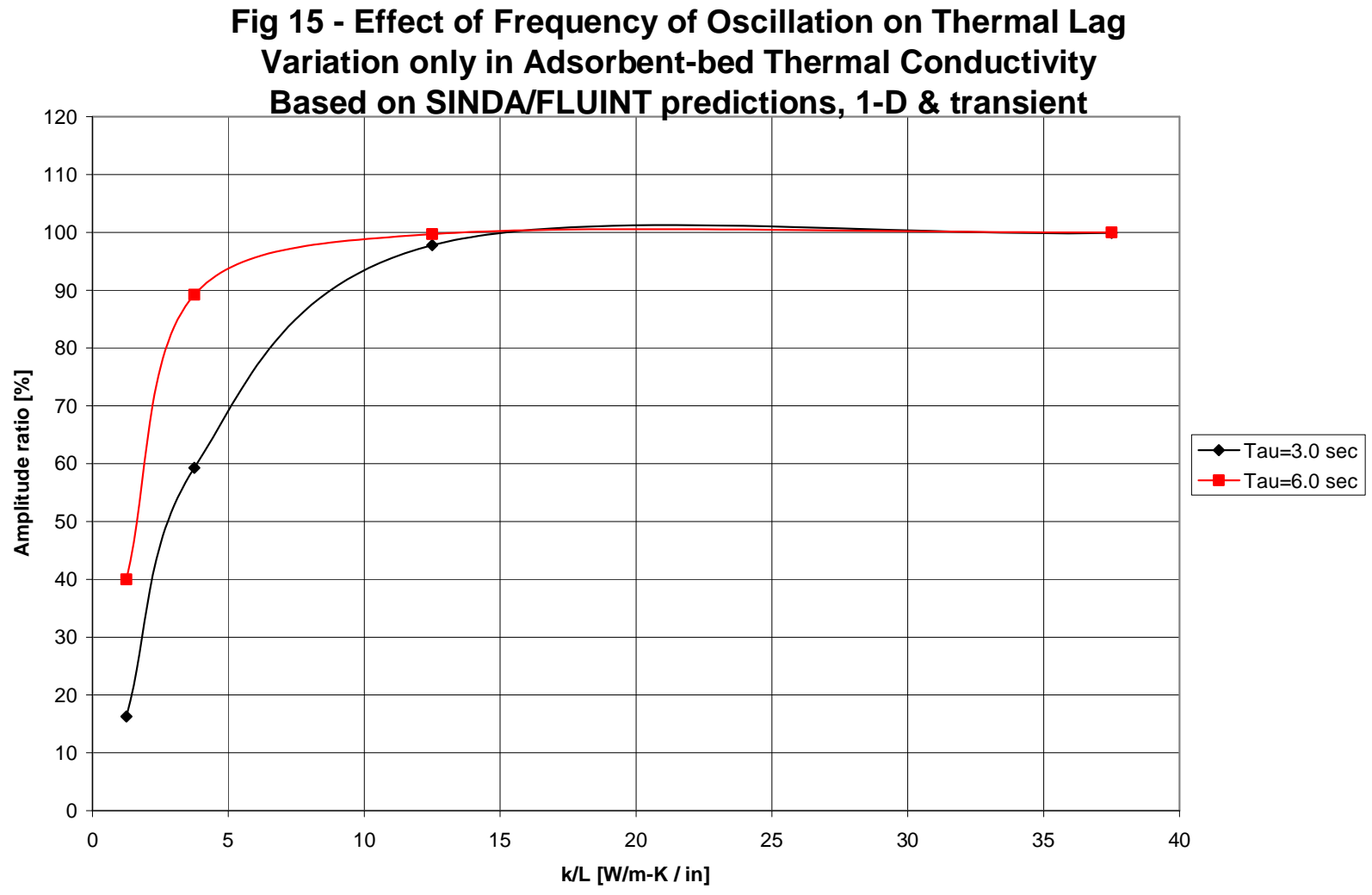

Figure 15. Amplitude ratio for 3 versus 6 seconds full cycle time

$-18-$

Project 41905, Upgrading Methane Using UltraFast Thermal Swing Adsorption, Velocys Inc. 


\section{Conclusions}

Thermal models of the microchannel thermal swing adsorption unit based on the use of a phase change heat exchange fluid offers new promise for the use of powder adsorbent beds. For thermal cycle times in the order of 3 to 6 seconds, acceptable thermal profiles have been modeled for microchannels.

For the powder adsorbent bed with a low thermal conductivity, on the order of $0.18 \mathrm{~W} / \mathrm{m}-\mathrm{K}$, an adsorbent gap in the range of 0.02 inch to 0.06 inch appear feasible for complete thermal cycle times of 3 to 6 seconds or longer.

Additional work is underway to rebaseline the powder adsorbent with fresh feed and then conduct comparison runs for capacity and performance with a series of feed contaminants. 


\section{Acronyms and Abbreviations}

$\begin{array}{ll}\text { Btu } & \text { British thermal unit } \\ \text { GHG } & \text { greenhouse gas } \\ \text { gm } & \text { gram } \\ \text { GWP } & \text { global warming potential } \\ \text { HPBV } & \text { high-performance butterfly valve } \\ \text { kg } & \text { kilogram } \\ \text { mg } & \text { milligram } \\ \text { MMSCFD } & \text { million standard cubic feet per day } \\ \text { MW } & \text { megawatts } \\ \text { NRU } & \text { nitrogen rejection unit } \\ \text { psig } & \text { pound per square inch gauge } \\ \text { SLPM } & \text { standard liters per minute } \\ \text { TSA } & \text { thermal swing adsorption }\end{array}$




\section{Public Recognition of the Project}

An oral presentation was made at the AIChE Spring meeting on the use of thermal swing adsorption in microchannels for upgrading coal-mine methane to natural gas pipeline.

A publication has been accepted for oral presentation ACHEMA 2006 in Frankfurt Germany on the use of thermal swing adsorption in a microchannel TSA unit for nitrogen rejection. 